monogamy is the best way of satisfying basic wants, and concludes that there are positive reasons for abandoning it, at least as a model for personal relationships: we should be openminded in order to allow maximum flexibility and diversity. Gregory whose bibliography lists only his own writings - suggests that, since marriage (sic) must fail, we now move on from sequential to concurrent marriage: we shall then avoid possessiveness and the jealousy generated by the suspicion or sense of being dispossessed. Brecher insists that marriage must have a public meaning, not determined by the intentions and characters of individuals. Hence its political value: marriage furthers a social ideology of ownership (since central to marriage is ownership of women by men); it helps to exclude women from public life; it is the engine of capitalist consumption. Marriage is therefore numbered amongst the 'morality-affecting harms', like 'racism' and 'sexism'. This is but a prolegomenon for a critique of marriage.

The volume does not tell us what philosophers learned from one another in their conference.

G R DUNSTAN Department of Theology, University of Exeter

\section{Death and deliverance. 'Euthanasia' in Germany 1900-1945}

\author{
Michael Burleigh, Cambridge, \\ Cambridge University Press, 1994, \\ 382 pages, $£ 35.00 \mathrm{hb}, £ 14.95 \mathrm{pb}$.
}

Fifty years after the collapse of the Third Reich, one may be forgiven for thinking that the subject of the Nazi policies of extermination had been worked over to exhaustion. The 'Holocaust' and the 'Final Solution' to wipe out the Jewish and other 'inferior' races have dominated attention, leaving some aspects of the subject comparatively neglected. Less attention has been given to attitudes in Germany towards the value of life in the early years of the century, especially in the hard economic climate during and after World War I. Did the Nazi doctrines spring up ready-made or was the seed already present in the German mind before the rise of Hitler? Most particularly, how did the medical profession, which fulfilled a key role in carrying out the policy, come to distort its ethical base so disastrously?

The author, Reader in International History at the London School of Economics, does not deal with the 'Final Solution' ie the 'Holocaust' except very briefly. This is deliberate since he has covered that ground in previous books (Germany Turns Eastwards, 1988 and The Racial State: Germany 1933-1945, 1991) and the book's title makes it clear that 'Euthanasia' is the topic, a policy which predated the 'final solution' and provided the techniques and mental set to accommodate it.

Burleigh begins by showing that the first questioning of the classical concept of euthanasia as a 'fine' or 'gentle' death began in the 1890 s with the concept of a 'life unworthy of life', and alarm at the intolerable economic burden on the state of the incurably ill and mentally defective. During World War I, rations were drastically reduced in mental asylums and mortality soared. Financial cutbacks led to gross overcrowding and understaffing.

In the 1920 s the debate intensified after the publication of Permission for the Destruction of Life Unworthy of Life by Karl Binding, a jurist, and Alfred Hoche, a psychiatrist. Building on a series of unimpeachably liberal premises, the tract systematically rehearsed a series of illiberal and crudely materialistic arguments in favour of involuntary euthanasia, using the economic burden on the state to outweigh the right to life of the individual. There was much criticism and, naturally, the 'slippery slope' argument appeared but the economic argument gained ground, accompanied by the first sinister appearance of crude Darwinism, arguing for sterilisation of those deemed to carry defective traits and the ending of the life of those deemed to be a burden to themselves and, particularly, to the state. They were selected by Hereditary Health Courts, set up to identify individuals for sterilisation or 'euthanasia'. Threeman teams of referees went round asylums selecting cases for transfer to asylums where those selected were deliberately allowed, or helped, to die. By 1938 defective children and Jews were being starved and dying of neglect, gassing or lethal injection in asylums. This was made possible by the poor quality of doctors and nurses in these institutions, the unfavoured rump of their professions, and the introduction of unsuitable staff from outside. After 1936, staffing was restricted to members of the SS.

While there was opposition from some quarters in the professions and from the asylums run by religious organisations, there seems to have been considerable acceptance and collusion and the SS was able to ride rough-shod over all opposition.

In 1939, Hitler formally instructed the implementation of a programme of euthanasia and wrote a note 'extending the powers of specific doctors in such a way that, after the most careful assessment of their condition, those suffering from illness deemed to be incurable may be granted a mercy death'. This led to the setting up of 'Aktion T-4' which remained an undercover organisation. The instruction was never enacted in law. The wishes of Hitler were simply indirectly interpreted as orders. Though they claimed that their selections were made with compassion and strict scientific rigour, choice was in fact made on the most haphazard grounds and very soon included the work-shy, trouble-makers and nonAryans. Each asylum was given an increasingly large quota of victims to find. Since there was no legal basis, tho psychiatrists had to provide certificates with fictitious causes of deatho Relatives who questioned why theif loved ones had suddenly died of 'heart failure' or 'pneumonia' received short shrift. Nevertheless, there was widespread alarm in the community and many suspected what was going on, not least because of the pungent smoke that arose from certain asylums which had become collecting centres for the condemned.

Though the churches remained equivocal, Bishop Galen of Münster was a longstanding critic. In 1941 he published a sermon condemning 'euthanasia'. It was widely circulated and the RAF dropped leaflets over Germany quoting it. Though many priests and laymen who repeated what the Bishop said were disciplined or sent to concentration camps, Bishop Galen was threatened but not sacked.

To promote public acceptance of the principle of 'life unworthy of life', films were made. At first these were crude documentaries, intercutting images designed to degrade, criminalise and dehumanise the mentally and physically handicapped in order to justify sterilising them. However, later more sophisticated feature films were made, with story-lines arguing the case for 'euthanasia', but showing a very sanitised version of the actual mechanics of gassing. 
The 'euthanasia' programme led to the killing of wounded or insane returning servicemen, of foreign workers who were no longer fit for work, of racial minorities in conquered territories - especially the USSR, and finally, to the mass slaughter in the concentration camps.

After the end of World War II, many of the psychiatrists and laymen responsible were known and a few were tried and condemned, but large numbers escaped punishment. The medical profession of their generation does not come out of the story well, since the perpetrators had no difficulty in finding colleagues to certify them 'unfit for trial'.

Burleigh has trawled the massive archive which records the rise of the programme with meticulous scholarship. The quotations from the many participants, particularly from the victims and their relatives, give a clear picture of the atmosphere at the time as well as of the reactions to the ethical arguments, usually clothed in pseudoscientific or utilitarian jargon. $\mathrm{He}$ writes in tones of barely concealed fury at the brazen duplicity of those responsible for a deliberate policy of murder.

The euthanasia debate which is still alive today and, hopefully, being conducted in a more ethical way, will benefit from another look at the German experience, which this book so vividly recaptures. It is a gripping read.

DUNCAN FORREST

Medical Foundation for the Care of Victims of Torture, London

\section{Doctors, dilemmas, decisions}

Ben Essex, London, BMJ Publishing Group, 1994, 301 pages, £22.95.

This book sets out to analyse decisionmaking in general practice. It is not, as the jacket claims, the first book on the subject. It is, however, an entirely new concept, based on over 200 case histories from the author's experience which pose dilemmas. From these are drawn some 900 'rules' which the author has devised to help in reaching decisions.

The format of the book initially is somewhat daunting and rigid with boxed and tabulated information on every page. However, the case histories, which represent the whole range of physical, psychological and social pathology of general practice make such compelling reading and provide so vivid a picture of the immense variety that is general practice that the reader is led on despite the complexity of layout. Thus initial reservations about the style of the book are quickly dispelled.

One's first reaction is surprise at being asked to review this book for the fournal of Medical Ethics since it seemed to deal more with management and clinical decision-making than with conventional ethical problems. Later, however, the book deals with HIV/AIDS, with confidentiality, compliance, patient autonomy and consent so that ethical dilemma, which is present in even the simplest of cases if it is looked for, was plentiful. Where such problems were spelled out they tended to be dealt with in terms of law and guidelines from bodies such as the Royal College of General Practitioners (RCGP) and the British Medical Association (BMA) rather than from the standpoint of moral philosophy. This was a deficiency and reference to any of the many texts on ethics was noticeably deficient. Indeed, references as a whole were few, with many chapters without any and only that on 'protocols and policies' with any amount. The 'rules', the author claims, were tested through teaching and research, and would be more acceptable had they been called guidelines, for 'rule' implies a rigidity which is rarely applicable to the everchanging, infinitely variable problems of general practice. Again, with increasing familiarity with the author's reasoning these reservations eased so that on finishing the book I felt I wanted to start reading it all over again.

The author claims justly that this is a book for everyone. Certainly this retired academic found much to be nostalgic about while reading it; for medical teachers preparing for their classes of trainees or students, and above all for those preparing for membership of the RCGP, this book is an excellent method of studying and revising general practice. Originality, almost to the point of idiosyncrasy, makes thought-provoking reading. Well done, Dr Essex and thank you for a very stimulating view of what you rightly describe as 'one of the most intellectually demanding specialities in medicine'.

Retired Professor of General Practice
Procuring organs by transplant: the debate over non-heartbeating cadaver protocols

Edited by Robert M Arnold, Stuart J Youngner, Renie Schapiro and Carol Mason Spicer, Baltimore and London, Johns Hopkins University Press, 1995, 249 pages, pb.

The nineteen papers in this volume address ethical issues surrounding the procurement of organs from 'non-heart-beating cadaver donors' (NHBCDs). These are patients who have been declared dead by cardiopulmonary criteria rather than neurologic criteria. The main impetus for NHBCD procurement stems from the University of Pittsburgh Medical Center's Protocol of 1993, whose move towards cardiocentric criteria for death was in response to increasing pressure for more organs. The papers in this collection, by doctors and bioethicists who support the protocol, stress benefits associated with increased procurement rates; criticse raise ethical questions concerning the motives for shifting the boundary between life and death and raise further doubts concerning psychological and social policy consequences of the move towards cardiocentric criteria for death.

Prior to the widespread acceptance of neurologic criteria for death NHBCDs were the primary source of 'cadaveric' donation. But this method fell into disrepute with the establishment of irreversible loss of brain function as the boundary between life and death. The revival of NHBCDs as organ sources in the late 1980 s is bound up with improvements in techniques for the preservation of organs following cardiopulmonary cessation and protocols for 'controlled donation' which allow patients and their families to donate organs after a decision has been implemented to forego life-sustaining treatment. A typical example would involve cessation of heart-beat during an operation, where a prior directive to forego resuscitation was in force, followed by in situ cooling of the kidneys and removal of transplantable organs. Protocols which authorise organ removal following cardiac arrest do not address the issue of brain death, and represent an alternative concept of death based on 